\title{
Low-Dose Intravenous Paracetamol for Patent Ductus Arteriosus in Indomethacin-Resistant or Contraindicated Preterm Infants: Three Cases Reports
}

\author{
Shun Matsumura, MD ${ }^{1}$ Ayumi Oshima, MD ${ }^{1} \quad$ Sumie Fujinuma, MD ${ }^{1} \quad$ Kosuke Tanaka, MD \\ Nobuhiko Nagano, MD, PhD ${ }^{1}$ Fuyu Miyake, $\mathrm{MD}^{1}$ Satoshi Masutani, MD, PhD ${ }^{1}$ \\ Masanori Tamura, MD, PhD ${ }^{1}$ Keiko Ueda, MD $^{2}$ Fumihiko Namba, MD, PhD ${ }^{1}$ \\ ${ }^{1}$ Department of Pediatrics, Saitama Medical Center, Saitama Medical
University, Kawagoe, Saitama, Japan
${ }^{2}$ Clinical Research Support Center, The University of Tokyo Hospital,
Bunkyo, Tokyo, Japan \\ Address for correspondence Fumihiko Namba, MD, PhD, Department \\ of Pediatrics, Saitama Medical Center, Saitama Medical University, \\ 1981 Kamoda, Kawagoe, Saitama 350-8550, Japan \\ (e-mail: nambaf@saitama-med.ac.jp).
}

Am J Perinatol Rep 2017;7:e230-e233.

\begin{abstract}
Background Although indomethacin (IND) is the standard treatment for hemodynamically significant patent ductus arteriosus (hsPDA) in Japan, it may be associated with renal impairment and gastrointestinal complications. The use of paracetamol for hsPDA closure has recently increased. Unlike IND, paracetamol does not have a peripheral vasoconstrictive effect and can be given to infants with contraindications to IND. Based on limited data available from randomized trials, paracetamol and IND seem to have similar effects. However, there have been no reports of the use of paracetamol for hsPDA in Japan.

Cases Our drug administration protocol was approved by the institutional ethics committee after purchasing a clinical trial insurance. In three premature infants in whom IND was contraindicated or ineffective, a $7.5 \mathrm{mg} / \mathrm{kg}$ of paracetamol was

Keywords

- indomethacin

- paracetamol

- patent ductus arteriosus

- premature infant

- surgical closure intravenously administered every 6 hour for 3 days after obtaining parental consents. A temporary hsPDA closure was observed in two of the three infants. However, all three infants eventually needed surgical closure. No side effects, such as hepatic and renal dysfunctions, and adverse events were reported.

Conclusion The intravenous administration of paracetamol was safe and feasible in premature infants with hsPDA. Future clinical trials with optimized dose and timing of administration are needed.
\end{abstract}

Maintaining the patency of ductus arteriosus (DA) is essential for fetal circulation and normal development of the fetus. In almost-term infants, the DA constricts and causes intraluminal ischemic hypoxia, which eventually leads to the closure and remodeling of the DA a few days after birth. The occurrence of patent DA (PDA) is inversely related to

received

August 3, 2017

accepted after revision

October 26, 2017
DOI https://doi.org/

10.1055/s-0037-1615260. ISSN 2157-6998. gestational age and weight, with a higher incidence in preterm infants. ${ }^{1}$ PDA is a significant cause of morbidity and mortality in preterm infants, including bronchopulmonary dysplasia, intraventricular hemorrhage, necrotizing enterocolitis, and acute renal failure due to increased pulmonary blood flow and focal organ ischemia. ${ }^{2-4}$ In Japan, the
Copyright $\odot 2017$ by Thieme Medical Publishers, Inc., 333 Seventh Avenue, New York, NY 10001, USA. Tel: +1(212) 584-4662.
License terms

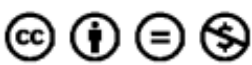


standard pharmacological treatment for hemodynamically significant PDA (hSPDA) closure involves the intravenous administration of a nonselective cyclooxygenase inhibitor indomethacin (IND). However, IND can be associated with potentially significant adverse effects, such as acute renal failure, necrotizing enterocolitis, and hypoglycemia. ${ }^{4}$

It is widely believed that the effect of paracetamol is a manifestation of inhibition of prostaglandin synthetase activity. Although its precise mechanism of action remains controversial, evidence suggests that paracetamol seems to act at the peroxidase segment of the enzyme, ${ }^{5}$ which indicates that paracetamol-mediated inhibition is facilitated by a reduction in the concentration of local peroxide. Paracetamol is widely used as an antipyretic analgesic for children. The efficacy of paracetamol in ductal constriction has been demonstrated in pregnant animal models. ${ }^{6}$ Furthermore, a case of in utero closure of the DA as a result of maternally used nimesulide and paracetamol has been reported. ${ }^{7}$ Oncel et al first reported on intravenous paracetamol treatment in the management of PDA in extremely low birth weight infants, ${ }^{8}$ and conducted a randomized controlled trial which compared oral paracetamol with ibuprofen in preterm infants and demonstrated that paracetamol may be a medical alternative in the management of PDA. ${ }^{9}$ Recently, some reports have also demonstrated the safety and efficacy of paracetamol treatment as a substitute for IND or ibuprofen in managing hsPDA. ${ }^{10-13}$ However, the safety and efficacy of paracetamol have not been reported in Japan. We present the first cases of hsPDA treated with intravenous paracetamol (Acelio, Terumo, Tokyo, Japan) in Japan. The protocol for the use of paracetamol was covered by the clinical trial insurance and was approved by the institutional review board (IRB) of Saitama Medical Center, Saitama Medical University. Parental consents were obtained before paracetamol administration.

\section{Cases}

- Table 1 summarizes the three cases. Infant A was a male at $25^{2} / 7$ weeks of gestational age (GA), with birth weight of $880 \mathrm{~g}$ [appropriate for date (AFD)] and an Apgar score of 5 at 1 minute and 7 at 5 minute. He had no malformation and received acute cardiopulmonary management. On days 0,2 , and 3, IND was intravenously administered to treat hsPDA, which induced acute renal failure on day 5, including a decreased urine output and elevated serum creatinine levels (2.82 $\mathrm{mg} / \mathrm{dL}$ ), without PDA closure. The diagnosis of hsPDA was made by echocardiographic findings in terms of ductal diameter $1.5 \mathrm{~mm}$, atrial: aortic root ratio $1.5 \mathrm{~mm}$, peak velocity in the diastole of the left pulmonary artery, and the evaluation of end-diastolic retrograde flow in the descending aorta and poor cardiac function in addition to clinical signs. ${ }^{14}$ From days 5 to 7 , a $7.5 \mathrm{mg} / \mathrm{kg}$ of paracetamol was intravenously administered every 6 hour for 3 days and PDA closure was confirmed using echocardiography on day 7. On day 16, PDA reopened and paracetamol was readministered for 3 days because of consistent high serum creatinine levels $(1.35 \mathrm{mg} / \mathrm{dL})$. During the second course of intravenous paracetamol treatment, the DA diameter remained unchanged, which enlarged to $2.0 \mathrm{~mm}$ after the therapy. A surgical DA closure was performed on day 27. In our institution, surgical ligation of PDA is only undertaken in patients when medical treatment has failed and if the patient requires extensive respiratory support or is unable to be weaned off a ventilator. During the two courses of intravenous paracetamol treatment, no adverse events, such as elevated hepatic enzyme and hypothermia, were observed.

Infant B was a female at $25^{3} / 7$ weeks of GA, with a birth weight of $715 \mathrm{~g}$ (AFD) and an Apgar score of 4 at 1 minute and 7 at 5 minute. She had no malformation and received acute cardiopulmonary management and antibiotic treatment for intrauterine infection. On days 0 and 2, IND was administered for hsPDA, and PDA closure was confirmed using echocardiography on day 3. The PDA reopened on day 7. Because four courses of IND administration were ineffective, a $7.5 \mathrm{mg} / \mathrm{kg}$ of paracetamol was intravenously administered every 6 hour for 3 days starting from day 20. The DA diameter remained unchanged and required a surgical closure on day 24. During this one course of intravenous paracetamol treatment, no adverse events were observed.

Infant $C$ was a female at $26^{3} / 7$ weeks of GA, with a birth weight of $890 \mathrm{~g}$ (AFD) and an Apgar score of 4 at 1 minute and 6 at 5 minute. She received acute cardiopulmonary management and had a large muscular ventricular septal defect $(2.5 \mathrm{~mm})$.

Table 1 Summary of the three cases

\begin{tabular}{|l|l|l|l|l|l|l|l|l|l|l|}
\hline Case & $\begin{array}{l}\text { GA } \\
\text { (wk) }\end{array}$ & $\begin{array}{l}\text { BW } \\
\text { (g) }\end{array}$ & $\begin{array}{l}\text { Contrain- } \\
\text { dication } \\
\text { to indo- } \\
\text { methacin }\end{array}$ & $\begin{array}{l}\text { Age when } \\
\text { treatment } \\
\text { was started } \\
\text { (d) }\end{array}$ & $\begin{array}{l}\text { Duration } \\
\text { of treat- } \\
\text { ment (d) }\end{array}$ & $\begin{array}{l}\text { Pretreat- } \\
\text { ment DA } \\
\text { diameter } \\
\text { (mm) }\end{array}$ & $\begin{array}{l}\text { Pretreat- } \\
\text { ment } \\
\text { LA/Ao }\end{array}$ & $\begin{array}{l}\text { Posttreat- } \\
\text { ment PDA } \\
\text { status }\end{array}$ & $\begin{array}{l}\text { Adverse } \\
\text { events }\end{array}$ & $\begin{array}{l}\text { Surgical } \\
\text { ligation }\end{array}$ \\
\hline $\mathrm{A}$ & $25^{2} / 7$ & 880 & $\begin{array}{l}\text { Acute } \\
\text { renal } \\
\text { failure }\end{array}$ & 05 & 6 & 1.3 & 1.23 & $\begin{array}{l}\text { Temporary } \\
\text { closure }\end{array}$ & - \\
\hline $\mathrm{B}$ & $25^{3} / 7$ & 715 & Ineffective & 20 & 3 & 1.3 & 1.71 & Ineffective & - \\
\hline $\mathrm{C}$ & $26^{3} / 7$ & 890 & $\begin{array}{l}\text { Acute } \\
\text { renal } \\
\text { failure }\end{array}$ & 12 & 6 & 1.5 & 1.05 & $\begin{array}{l}\text { Temporary } \\
\text { closure }\end{array}$ & - & + \\
\hline
\end{tabular}

Abbreviations: BW, birth weight; DA, ductus arteriosus; GA, gestational age; LA/Ao, left atrial/aortic root ratio; PDA, patent ductus arteriosus. 
A pharmacological treatment for DA closure was tried to prevent the exacerbation of congestive heart failure. Despite two courses of IND administration, the DA diameter remained unchanged and decreased urine output and elevated serum creatinine levels $(2.02 \mathrm{mg} / \mathrm{dL}$ ) were observed. PDA closure was confirmed after red blood cell transfusion on day 11 . On day 12 , DA reopened; therefore, a $7.5 \mathrm{mg} / \mathrm{kg}$ of paracetamol was intravenously administered every 6 hour for 3 days, because of elevated serum creatinine levels $(2.04 \mathrm{mg} / \mathrm{dL})$. During paracetamol treatment, the DA diameter decreased from 1.5 to $0.7 \mathrm{~mm}$, which subsequently increased to $1.0 \mathrm{~mm}$ after the therapy. The second course of paracetamol treatment was started on day 16 . PDA temporarily closed on day 18 , which reopened on day 21 . No adverse events were observed during paracetamol treatment. Surgical DA closure was eventually required on day 61 after two courses of paracetamol treatment and three of IND treatment.

\section{Discussion}

Nonsteroidal anti-inflammatory drugs (NSAIDs), specifically IND and ibuprofen, have been the initial medications of choice for PDA closure. ${ }^{2-4}$ NSAIDs block prostaglandin E2 (PGE2) production by inhibiting the cyclooxygenase (COX) enzymes, and thereby facilitate the thickening of the lumen with ductal closure. Approximately 70 to $85 \%$ success rates of NSAIDs in PDA closure have been reported; ${ }^{4}$ however, the reopening rate of DA after the pharmacological treatment with these drugs is 20 to $35 \%{ }^{15,16}$ and they can cause weakened platelet aggregation, hyperbilirubinemia, peripheral vasoconstriction, and decreased organ blood flow with subsequent renal dysfunction and gastrointestinal perforations. ${ }^{2-4,17}$ Paracetamol has recently been considered as an alternative treatment for hsPDA because of its safety and effectiveness. ${ }^{18,19}$ El-Mashad et al compared the efficacy and side effects of IND, ibuprofen, and paracetamol for PDA closure in preterm neonates and concluded that paracetamol is as effective as IND and ibuprofen and has fewer side effects mainly on renal function, platelet count, and gastrointestinal bleeding. ${ }^{12}$ However, the use of intravenous paracetamol for treating hsPDA has not yet been reported in Japan. Here, we reported the cases of three extremely low birth weight infants with hsPDA who were treated with intravenous paracetamol because of contraindication or resistance to IND. Although all infants eventually needed surgical treatment, temporary closure and no adverse events were observed during the pharmacological treatment with low-dose intravenous paracetamol, thereby suggesting that paracetamol treatment might delay the surgery date for DA closure. The dosage and timing of administration seemed to be the key factors contributing to the efficacy of paracetamol. In recently conducted clinical trials, a $60 \mathrm{mg} / \mathrm{kg} /$ day of paracetamol was intravenously administered for 3 days. ${ }^{10-12} \mathrm{How}$ ever, we selected a lower dosage of $30 \mathrm{mg} / \mathrm{kg} / \mathrm{day}$ ( $7.5 \mathrm{mg} / \mathrm{kg} /$ dose $\times 4$ /day) for 3 days, on the basis of its package insert in Japan, which recommends a dose of $7.5 \mathrm{mg} / \mathrm{kg}$ every 6 hours for term neonates up to infants weighing $10 \mathrm{~kg}$. In our three cases, a dose of $7.5 \mathrm{mg} / \mathrm{kg}$ every 6 hours was used according to our treatment protocol, which was covered by the clinical trial insurance and was approved by the IRB. Therefore, we could not increase the dose or the duration of paracetamol therapy. With regard to the timing, a prospective observational cohort study reported that the use of paracetamol after ibuprofen treatment failure was ineffective for PDA closure in very low birth weight infants. From these findings, the authors concluded that paracetamol treatment for PDA closure cannot be recommended for infants with a postnatal age of $>2$ weeks and that an early paracetamol treatment might be more effective. ${ }^{11}$ In the present cases, the starting days of paracetamol administration were days 5 and 16 in infant $A$, day 20 in infant $B$, and days 12 and 16 in infant $C$. Because paracetamol treatment was not the first line treatment in our administration protocol, the timing of dosage was necessarily late because of which our protocol of intravenous paracetamol eventually could not avoid a surgical treatment.

We showed temporary DA closure and no short-term adverse events during the pharmacological treatment with intravenous paracetamol. However, in view of a recent report in mice of adverse effects on the developing brain from paracetamol, ${ }^{20}$ and another report of an association between prenatal paracetamol and the development of autism or autism spectrum disorder in childhood, ${ }^{21}$ long-term follow-up to at least 18 to 24 months postnatal age must be incorporated in any studies of paracetamol in the newborn population. Recently, a follow-up study conducted by Oncel et al revealed that the neurodevelopmental outcomes did not differ among the preterm infants who receive either paracetamol or ibuprofen at 18 to 24 months' corrected age. ${ }^{22}$ Follow-up will be also necessary for our three cases to investigate long-term adverse events related to paracetamol.

\section{Conclusion}

These are the first case reports of hsPDA in preterm infants treated with low-dose intravenous paracetamol in Japan. We believe that intravenous paracetamol can be used for hsPDA closure in premature neonates when IND treatment is unsuccessful and when the only other therapeutic option is surgery. Further dose-escalation studies and subsequent prospective, randomized controlled trials are needed to evaluate the efficacy of intravenous paracetamol for hsPDA closure.

\section{References}

1 Fanaroff AA, Hack M, Walsh MC. The NICHD neonatal research network: changes in practice and outcomes during the first 15 years. Semin Perinatol 2003;27(04):281-287

2 Itabashi K, Ohno T, Nishida H. Indomethacin responsiveness of patent ductus arteriosus and renal abnormalities in preterm infants treated with indomethacin. J Pediatr 2003;143(02): 203-207

3 Hamrick SE, Hansmann G. Patent ductus arteriosus of the preterm infant. Pediatrics 2010;125(05):1020-1030

4 Johnston PG, Gillam-Krakauer M, Fuller MP, Reese J. Evidencebased use of indomethacin and ibuprofen in the neonatal intensive care unit. Clin Perinatol 2012;39(01):111-136

5 Grèen $K$, Drvota $V$, Vesterqvist O. Pronounced reduction of in vivo prostacyclin synthesis in humans by acetaminophen (paracetamol). Prostaglandins 1989;37(03):311-315 
6 Momma K, Takao A. Transplacental cardiovascular effects of four popular analgesics in rats. Am J Obstet Gynecol 1990;162(05): 1304-1310

7 Simbi KA, Secchieri S, Rinaldo M, Demi M, Zanardo V. In utero ductal closure following near-term maternal self-medication with nimesulide and acetaminophen. J Obstet Gynaecol 2002;22(04):440-441

8 Oncel MY, Yurttutan S, Degirmencioglu H, et al. Intravenous paracetamol treatment in the management of patent ductus arteriosus in extremely low birth weight infants. Neonatology 2013;103(03):166-169

9 Oncel MY, Yurttutan S, Erdeve O, et al. Oral paracetamol versus oral ibuprofen in the management of patent ductus arteriosus in preterm infants: a randomized controlled trial. J Pediatr 2014;164 (03):510-4.e1

10 Ohlsson A, Shah PS. Paracetamol (acetaminophen) for patent ductus arteriosus in preterm or low-birth-weight infants. Cochrane Database Syst Rev 2015;(03):CD010061

11 Terrin G, Conte F, Oncel MY, et al. Paracetamol for the treatment of patent ductus arteriosus in preterm neonates: a systematic review and meta-analysis. Arch Dis Child Fetal Neonatal Ed 2016;101(02):F127-F136

12 El-Mashad AE, El-Mahdy H, El Amrousy D, Elgendy M. Comparative study of the efficacy and safety of paracetamol, ibuprofen, and indomethacin in closure of patent ductus arteriosus in preterm neonates. Eur J Pediatr 2017;176(02):233-240

13 Härkin P, Härmä A, Aikio O, et al. Paracetamol accelerates closure of the ductus arteriosus after premature birth: a randomized trial. J Pediatr 2016;177:72-77.e2
14 Jain A, Shah PS. Diagnosis, evaluation, and management of patent ductus arteriosus in preterm neonates. JAMA Pediatr 2015;169 (09):863-872

15 Bhat R, Das UG. Management of patent ductus arteriosus in premature infants. Indian J Pediatr 2015;82(01):53-60

16 Weiss H, Cooper B, Brook M, Schlueter M, Clyman R. Factors determining reopening of the ductus arteriosus after successful clinical closure with indomethacin.J Pediatr 1995;127(03):466-471

17 Zecca E, Romagnoli C, De Carolis MP, Costa S, Marra R, De Luca D. Does ibuprofen increase neonatal hyperbilirubinemia? Pediatrics 2009;124(02):480-484

18 Tan ZH, Baral VR. Principles of clinical management of patent ductus arteriosus in extremely preterm neonates. Curr Pediatr Rev 2016;12(02):83-97

19 Rostas SE, McPherson CC. Pharmacotherapy for patent ductus arteriosus: current options and outstanding questions. Curr Pediatr Rev 2016;12(02):110-119

20 Viberg H, Eriksson P, Gordh T, Fredriksson A. Paracetamol (acetaminophen) administration during neonatal brain development affects cognitive function and alters its analgesic and anxiolytic response in adult male mice. Toxicol Sci 2014; 138(01):139-147

21 Bauer AZ, Kriebel D. Prenatal and perinatal analgesic exposure and autism: an ecological link. Environ Health 2013;12:41

22 Oncel MY, Eras Z, Uras N, Canpolat FE, Erdeve O, Oguz SS. Neurodevelopmental outcomes of preterm infants treated with oral paracetamol versus ibuprofen for patent ductus arteriosus. Am J Perinatol 2017;34(12):1185-1189 